\title{
Dietary intake of total marine $n-3$ polyunsaturated fatty acids, eicosapentaenoic acid, docosahexaenoic acid and docosapentaenoic acid and the risk of acute coronary syndrome - a cohort study
}

\author{
Albert M. Joensen ${ }^{1,2}$, Erik B. Schmidt ${ }^{1,2}$, Claus Dethlefsen ${ }^{2}$, Søren P. Johnsen ${ }^{3}$, Anne Tjønneland ${ }^{4}$, \\ Lars H. Rasmussen ${ }^{1}$ and Kim Overvad ${ }^{1}$ \\ ${ }^{1}$ Department of Cardiology, Aalborg Hospital, Aarhus University Hospital, Aalborg, Denmark \\ ${ }^{2}$ Centre for Cardiovascular Research Aalborg Hospital, Aarhus University Hospital, Aalborg, Denmark \\ ${ }^{3}$ Clinical Epidemiology, Aalborg Hospital, Aarhus University Hospital, Aalborg, Denmark \\ ${ }^{4}$ Danish Cancer Society, Institute of Cancer Epidemiology, Copenhagen, Denmark \\ (Received 21 May 2009 - Revised 14 July 2009 - Accepted 26 August 2009 - First published online 14 October 2009)
}

\begin{abstract}
Dietary intake of marine $n-3$ PUFA has been negatively associated with the risk of CHD among subjects with known CHD, whereas an effect in healthy subjects is less documented. We assessed the hypothesis that dietary intake of marine $n$ - 3 PUFA is negatively associated with the risk of acute coronary syndrome (ACS) in healthy subjects. In the Danish Diet, Cancer and Health cohort study, 57053 participants were enrolled. Dietary intake of total n-3 PUFA, including EPA, docosapentaenoic acid (DPA) and DHA, was assessed. During a mean follow-up period of 7.6 years, we identified all cases $(n$ 1150) from this cohort with an incident ACS diagnosis in the Danish National Patient Registry or the Cause of Death Registry. Diagnoses were verified through medical record review. In Cox proportional hazard models, we adjusted for established risk factors for CHD. Men in the four highest quintiles of $n$-3 PUFA intake ( $>0.39 \mathrm{~g} n-3$ PUFA per d) had a lower incidence of ACS compared with men in the lowest quintile. The hazard ratio was 0.83 (95\% CI 0.67, 1.03) when we compared men in the second lowest and lowest quintile of $n-3$ PUFA intake. Higher intake of $n-3$ PUFA did not strengthen this association. Associations for EPA, DPA and DHA were all negative, but less consistent. No convincing associations were found among women. In conclusion, we found borderline significant negative associations between the intake of marine $n-3$ PUFA and ACS among healthy men.
\end{abstract}

n-3 Fatty acids: Acute coronary syndrome: Cohort studies

Acute coronary syndrome (ACS), including unstable angina pectoris and non-fatal and fatal myocardial infarction (MI), is a leading cause of morbidity and mortality. Although the incidence of ACS has declined during the last decade, it is still very important to identify modifiable risk factors to further reduce the incidence ${ }^{(1)}$.

Several studies have reported that intake of fish with a high content of marine $n-3$ PUFA is inversely associated with the risk of sudden cardiac death ${ }^{(2-8)}$. The association between intake of marine $n-3$ PUFA and risk of non-fatal MI or ACS, however, remains unclear ${ }^{(3,9-15)}$. The marine $n-3$ PUFA EPA and DHA have anti-atherosclerotic, anti-thrombotic, anti-arrhythmic and anti-inflammatory effects that may explain a beneficial effect of seafood on $\mathrm{ACS}^{(16,17)}$. In contrast, the biological effects of the third major marine $n-3$ PUFA, docosapentaenoic acid (DPA), are virtually unknown.

Previous studies have mainly focused on intake of $n-3$ PUFA in patients with established CHD. Studies that have examined the intake of $n-3$ PUFA and the risk of MI or ACS among subjects without known CHD have given inconsistent results ${ }^{(2,18-22)}$. However, in a meta-analysis including twenty-five studies Harris et al. concluded that the tissue content of $n-3$ PUFA was consistently and significantly reduced in patients experiencing CHD events ${ }^{(23)}$. Moreover, three recent case-control studies found that higher plasma concentrations of n-3 PUFA were associated with a lower risk of $\mathrm{ACS}^{(24,25)}$ or non-fatal $\mathrm{MI}^{(26)}$ although not uniformly reported ${ }^{(27)}$. Finally, the only randomised clinical trial including healthy men and women also indicated that there may be a negative association between dietary intake of $n-3$ PUFA and the risk of $\mathrm{ACS}^{(14)}$.

We have tested the hypothesis that intake of marine $n-3$ PUFA is negatively associated with the risk of ACS in a Danish cohort with well-validated data on the intake of $n-3$ PUFA, information regarding potential confounders and validated data on the incidence of ACS.

Abbreviations: ACS, acute coronary syndrome; DPA, docosapentaenoic acid; MI, myocardial infarction.

* Corresponding author: Dr A. M. Joensen, fax +45 99326861, email albert.marni.joensen@rn.dk 


\section{Materials and methods}

Diet, Cancer and Health is a prospective Danish cohort study with the primary objective of investigating the aetiological role of diet in the development of cancer. The study has been described in detail elsewhere ${ }^{(28)}$. Briefly, between December 1993 and May 1997, a total of 80996 men and 79729 women aged 50-64 years were invited to participate in the study; 27178 men and 29875 women accepted the invitation. Eligible cohort members were all born in Denmark, lived in the urban areas of Copenhagen and Aarhus, and were not, at the time of invitation, registered with a cancer diagnosis in the Danish Cancer Registry. All participants gave written informed consent. The study Diet, Cancer and Health has been approved by the relevant Scientific Committees and the Danish Data Protection Agency.

All participants were asked to fill in a detailed FFQ including 192 items, of which twenty-four concerned intake of fish. The development and validation of the FFQ have been described elsewhere ${ }^{(29,30)}$. The content of EPA, DHA and DPA in the diet was calculated with the computer program 'FoodCalc' (Center for Applied Computer Science, University of Copenhagen, Copenhagen, Denmark; www.ibt.ku.dk/ jesper/foodcalc) which is based on Danish food composition tables. Participants also reported their intake of fish oil capsules, but we did not have sufficient information on the content of $n$-3 PUFA in the fish oil capsules to add this to the intake of EPA, DHA and DPA from seafood.

In addition, participants filled in a questionnaire concerning lifestyle and medical history including information on smoking habits, physical activity during leisure time, length of education, history of diabetes mellitus and (for women) hormone replacement treatment. The questionnaires were checked by an interviewer during a clinic visit. At the same visit, body weight, height and blood pressure were measured, and biological material was collected.

Identification of cases with ACS has been described in detail elsewhere ${ }^{(31)}$. Briefly, we identified all participants in the Diet, Cancer and Health cohort who were registered with an incident discharge diagnosis of ACS in the Danish National Patient Registry from recruitment and until 1 January 2004. Medical records were retrieved and reviewed and patients were classified in accordance with the current recommendations of the American Heart Association and other major health organisations for use in epidemiological studies, as described by Luepker et al. ${ }^{(32)}$. This classification is based on symptoms, signs, coronary biomarkers, and ECG and/or autopsy findings. Only patients that fulfilled the criteria of unstable angina pectoris, non-fatal MI or fatal MI were included as cases. Furthermore, we included participants registered with ACS as cause of death in the Causes of Death Registry without prior registration of incident disease.

\section{Statistical analyses}

Associations between intake of $n$ - 3 PUFA and ACS were illustrated using categorical exposure measures. In order to achieve the strongest possible statistical power, quintiles were defined according to the distribution of intake among cases. We calculated incidence rate ratios using Cox proportional hazards models with age as the time axis allowing for delayed entry.
We performed multivariate analyses including the following known risk factors for CHD: smoking (never, former, current, $1-14,15-24$ or $>24 \mathrm{~g}$ tobacco per $\mathrm{d})$; BMI $(<25,25-30$ and $>30 \mathrm{~kg} / \mathrm{m}^{2}$ ); duration of moderate to vigorous physical activity ( $<3.5$ or $\geq 3.5 \mathrm{~h}$ per week); history of diabetes mellitus (yes/no); systolic blood pressure (modelled as a restricted cubic spline); total cholesterol (linear variable); alcohol consumption (linear variable); total intake of fruit, vegetables, saturated fat, monounsaturated fat and of $n-6$ PUFA (all modelled as restricted cubic splines). For women we also adjusted for hormone replacement therapy (yes/no). We further stratified by intake of fish oil capsules (yes/no) in our statistical analyses. If information regarding one or more of the potential confounders was missing, the subject was excluded from the statistical analyses.

Data were analysed for total intake of marine $n-3$ PUFA and for EPA, DHA and DPA separately. Model adequacy was assessed graphically and found appropriate in all analyses. Analyses were done using STATA (version 9.0; StataCorp LP, College Station, TX, USA).

\section{Results}

In total, 1619 individuals were excluded from the present study because they did not fill in the questionnaires or had a diagnosis of ACS or cancer before entry into the study.

We identified 1654 participants in Diet, Cancer and Health with an incident diagnosis of ACS in the Danish National Patient Registry after recruitment. We were not able to retrieve the medical records or had insufficient information in 103 patients who were subsequently excluded from the statistical analyses; of the remaining 1551 patients, 1059 individuals fulfilled the criteria for ACS. Among cases, twenty individuals were excluded because their ACS was likely to have been caused by a medical-related procedure, for example, major surgery. From the Causes of Death Registry we included 111 participants registered with ACS as cause of death without prior registration of incident disease.

We excluded 946 participants, among these twenty-six cases, from the statistical analyses because information on one or more of the potential confounders was missing. In total, we included sixty-two cases with unstable angina pectoris, 885 with non-fatal MI and 177 with fatal MI during a mean follow-up period of 7.6 years. The incidence rate of ACS for men was $4.4(95 \%$ CI 4.1, 4.7) events per 1000 individual years, and for women $1.2(95 \%$ CI $1 \cdot 1,1.4)$ events per 1000 individual years.

Baseline characteristics of the cohort and cases for each sex are shown in Table 1.

The prevalence of established risk factors for CHD (current smoking, physical inactivity, overweight, systolic blood pressure $>140 \mathrm{mmHg}$, hypercholesterolaemia and diabetes mellitus) was higher among cases compared with the cohort as a whole.

The median intake of total $n-3$ PUFA, EPA, DHA and DPA was the same for the cases as for the cohort (Table 2).

Among men we found a borderline statistically significant negative association between total intake of marine $n-3$ PUFA and incidence of ACS. Men in the four highest quintiles of $n$-3 PUFA intake (more than $0.39 \mathrm{~g} n$-3 PUFA per d) had an approximately $15 \%$ lower incidence of ACS compared with 
Table 1. Prevalence of risk factors for CVD among male and female participants and acute coronary syndrome (ACS) cases of the Danish Diet, Cancer and Health cohort study

(Medians with 25th and 75th percentiles or percentages)

\begin{tabular}{|c|c|c|c|c|c|c|c|c|}
\hline & \multicolumn{4}{|c|}{ Men } & \multicolumn{4}{|c|}{ Women } \\
\hline & \multicolumn{2}{|c|}{ Cohort (n 24 786) } & \multicolumn{2}{|c|}{ Cases $(n 852)$} & \multicolumn{2}{|c|}{ Cohort (n 29017 ) } & \multicolumn{2}{|c|}{ Cases $(n 272)$} \\
\hline & Median & $\begin{array}{l}\text { 25th, } 75 \text { th } \\
\text { percentiles }\end{array}$ & Median & $\begin{array}{l}\text { 25th, } 75 \text { th } \\
\text { percentiles }\end{array}$ & Median & $\begin{array}{l}\text { 25th, } 75 \text { th } \\
\text { percentiles }\end{array}$ & Median & $\begin{array}{l}\text { 25th, } 75 \text { th } \\
\text { percentiles }\end{array}$ \\
\hline Age at enrolment (years) & $55 \cdot 9$ & $52 \cdot 6,60 \cdot 1$ & $58 \cdot 4$ & $54 \cdot 2,62 \cdot 0$ & $56 \cdot 2$ & $52 \cdot 8,60 \cdot 4$ & $59 \cdot 8$ & $56 \cdot 0,62 \cdot 4$ \\
\hline Current smokers (\%) & \multicolumn{2}{|r|}{39.5} & \multicolumn{2}{|r|}{$57 \cdot 9$} & \multicolumn{2}{|r|}{$32 \cdot 8$} & \multicolumn{2}{|r|}{$58 \cdot 3$} \\
\hline Physical activity $<3.5 \mathrm{~h}$ per week (\%) & \multicolumn{2}{|r|}{$62 \cdot 0$} & \multicolumn{2}{|r|}{$65 \cdot 9$} & \multicolumn{2}{|r|}{$59 \cdot 0$} & \multicolumn{2}{|r|}{$66 \cdot 4$} \\
\hline $\mathrm{BMI}>25 \mathrm{~kg} / \mathrm{m}^{2}(\%)$ & \multicolumn{2}{|r|}{$64 \cdot 7$} & \multicolumn{2}{|r|}{$72 \cdot 7$} & \multicolumn{2}{|r|}{$48 \cdot 2$} & \multicolumn{2}{|r|}{$62 \cdot 1$} \\
\hline Total cholesterol $(\mathrm{mmol} / \mathrm{l})$ & 5.9 & $5 \cdot 2,6 \cdot 7$ & $6 \cdot 3$ & $5 \cdot 6,7 \cdot 1$ & $6 \cdot 2$ & $5 \cdot 4,7 \cdot 0$ & $6 \cdot 6$ & $6 \cdot 0,7 \cdot 5$ \\
\hline Systolic blood pressure $(\mathrm{mmHg})$ & 140 & 128,154 & 149 & 136,161 & 136 & 122,151 & 152 & 136,166 \\
\hline Diabetes mellitus (\%) & \multicolumn{2}{|r|}{2.6} & \multicolumn{2}{|r|}{$5 \cdot 3$} & \multicolumn{2}{|r|}{1.5} & \multicolumn{2}{|r|}{$5 \cdot 2$} \\
\hline Education $<8$ years $(\%)$ & \multicolumn{2}{|r|}{$34 \cdot 2$} & \multirow{2}{*}{\multicolumn{2}{|c|}{$\begin{array}{c}46 \cdot 4 \\
-\end{array}$}} & \multirow{2}{*}{\multicolumn{2}{|c|}{$\begin{array}{l}31 \cdot 3 \\
44 \cdot 0\end{array}$}} & \multirow{2}{*}{\multicolumn{2}{|c|}{$\begin{array}{l}49 \cdot 6 \\
46 \cdot 1\end{array}$}} \\
\hline Hormone replacement therapy (\%) & \multicolumn{2}{|r|}{-} & & & & & & \\
\hline Vegetables $(\mathrm{g} / \mathrm{d})$ & 149 & 97,212 & 129 & 83,191 & 168 & 110,238 & 141 & 88,197 \\
\hline Fruit $(g / d)$ & 113 & 51,190 & 98 & 41,182 & 168 & 95,271 & 150 & 78,238 \\
\hline SFA $(g / d)$ & 32 & 26,40 & 32 & 26,40 & 23 & 19,29 & 24 & 18,29 \\
\hline MUFA $(g / d)$ & 36 & 29,45 & 36 & 28,45 & 28 & 21,35 & 27 & 20,36 \\
\hline Total $n-6$ PUFA $(\mathrm{g} / \mathrm{d})$ & $12 \cdot 3$ & $9 \cdot 4,15 \cdot 9$ & $12 \cdot 1$ & $9 \cdot 1,15 \cdot 5$ & 9.5 & $7 \cdot 2,12 \cdot 6$ & 9.4 & $9 \cdot 4,12 \cdot 0$ \\
\hline Alcohol $(\mathrm{g} / \mathrm{d})$ & $19 \cdot 5$ & $3 \cdot 6,62 \cdot 6$ & $17 \cdot 3$ & $7 \cdot 5,36 \cdot 8$ & $9 \cdot 3$ & $2 \cdot 9,17 \cdot 1$ & $5 \cdot 7$ & $1 \cdot 8,13 \cdot 3$ \\
\hline Total energy $(\mathrm{MJ} / \mathrm{d})$ & $10 \cdot 8$ & $9 \cdot 2,12 \cdot 6$ & $10 \cdot 6$ & $9 \cdot 0,12 \cdot 4$ & 8.5 & $7 \cdot 2,10 \cdot 1$ & $8 \cdot 1$ & $6.9,9.6$ \\
\hline Fish oil capsules (\%) & \multicolumn{2}{|r|}{$15 \cdot 8$} & \multicolumn{2}{|r|}{$14 \cdot 2$} & \multicolumn{2}{|c|}{$17 \cdot 3$} & \multicolumn{2}{|r|}{$22 \cdot 1$} \\
\hline
\end{tabular}

men in the lowest quintile. Adjusting for potential confounding from both non-dietary and dietary risk factors did not substantially change this association (Table 3).

The estimated intakes of EPA, DHA and DPA were highly correlated (correlations: EPA to DHA, 0.97; EPA to DPA, 0.77; DHA to DPA, 0.83). When we examined the intake of EPA, DHA and DPA separately, we found approximately the same association to ACS as for intake of total marine n-3 PUFA, although DPA showed a somewhat weaker association to ACS than EPA and DHA. Stratification by intake of fish oil capsules did not substantially change the risk estimates (data not shown).

Stratification by time from recruitment until onset of ACS showed a more pronounced effect of marine $n-3$ PUFA on ACS for the group of cases with onset of ACS more than 2 years after recruitment compared with cases with less than 2 years of observation (data not shown).

When we restricted the analyses to MI cases (fatal and nonfatal), the associations between the intake of $n-3$ PUFA and MI were consistent, but the CI were wider (data not shown).
We found no consistent association between intake of marine $n-3$ PUFA and incidence of ACS among women (Table 4).

\section{Discussion}

We found a borderline significant negative association between dietary intake of marine $n-3$ PUFA and the incidence of ACS among men. There was, however, no clear doseresponse relationship. The results were the same for EPA, DHA and DPA and all findings were unaffected by adjustment for known non-dietary and dietary risk factors for CHD. No consistent associations were observed among women.

The present study had several strengths. We had detailed exposure information obtained before the ACS diagnosis. The questionnaire on food items was carefully developed and validated against two times $7 \mathrm{~d}$ of weighed diet records. Furthermore, a specific biomarker study validated the information on intake of fatty acids ${ }^{(33)}$. Only few subjects were lost during follow-up and a large number of cases developed

Table 2. Intake of total marine $n$-3 PUFA, EPA, DHA and docosapentaenoic acid (DPA) among male and female participants and acute coronary syndrome cases in the Danish Diet, Cancer and Health cohort study

(Medians with 25th and 75th percentiles)

\begin{tabular}{|c|c|c|c|c|c|c|c|c|}
\hline \multirow[b]{3}{*}{ Intake } & \multicolumn{4}{|c|}{ Men* } & \multicolumn{4}{|c|}{ Women* } \\
\hline & \multicolumn{2}{|c|}{ Cohort (n 24 786) } & \multicolumn{2}{|c|}{ Cases (n 852) } & \multicolumn{2}{|c|}{ Cohort (n 29 017) } & \multicolumn{2}{|c|}{ Cases (n 272) } \\
\hline & Median & $\begin{array}{l}\text { 25th, 75th } \\
\text { percentiles }\end{array}$ & Median & $\begin{array}{l}\text { 25th, 75th } \\
\text { percentiles }\end{array}$ & Median & $\begin{array}{l}\text { 25th, 75th } \\
\text { percentiles }\end{array}$ & Median & $\begin{array}{l}\text { 25th, } 75 \text { th } \\
\text { percentiles }\end{array}$ \\
\hline$n-3$ PUFA (g/d) & 0.70 & $0.47,1.00$ & 0.68 & $0.44,0.97$ & 0.57 & $0.38,0.83$ & 0.58 & $0.37,0.82$ \\
\hline $\operatorname{EPA}(\mathrm{g} / \mathrm{d})$ & 0.18 & $0.11,0.27$ & 0.18 & $0.10,0.27$ & 0.15 & $0.09,0.23$ & 0.15 & $0.05,0.31$ \\
\hline $\mathrm{DHA}(\mathrm{g} / \mathrm{d})$ & 0.43 & $0.29,0.63$ & 0.42 & $0.26,0.61$ & 0.36 & $0.24,0.52$ & 0.37 & $0.24,0.52$ \\
\hline DPA (g/d) & 0.08 & $0.06,0.10$ & 0.08 & $0.06,0.10$ & 0.06 & $0.04,0.08$ & 0.06 & $0.04,0.08$ \\
\hline
\end{tabular}

*There were no significant differences between groups. 
Table 3. Hazard ratios (HR) of acute coronary syndrome associated with intake of total marine $n-3$ PUFA, EPA, DHA and docosapentaenoic acid (DPA) among male participants in the Danish Diet, Cancer and Health cohort study ${ }^{\star}$

(Hazard ratios and $95 \%$ confidence intervals)

\begin{tabular}{|c|c|c|c|c|}
\hline Quintile & $\mathrm{HR}$ & $95 \% \mathrm{Cl}$ & HR (adjusted)† & $95 \% \mathrm{Cl}$ \\
\hline \multicolumn{5}{|l|}{$n$-3 PUFA } \\
\hline $0.00-0.39 \mathrm{~g} / \mathrm{d}$ & 1 & & 1 & \\
\hline $0.39-0.58 \mathrm{~g} / \mathrm{d}$ & 0.82 & $0.67,1.02$ & 0.83 & $0.67,1.03$ \\
\hline $0.58-0.79 \mathrm{~g} / \mathrm{d}$ & 0.77 & $0.62,0.95$ & 0.81 & $0.65,1.01$ \\
\hline $0.79-1.08 \mathrm{~g} / \mathrm{d}$ & 0.87 & $0.70,1.07$ & 0.90 & $0.71,1.13$ \\
\hline$>1.08 \mathrm{~g} / \mathrm{d}$ & 0.81 & $0.66,1.01$ & 0.81 & $0.64,1.04$ \\
\hline \multicolumn{5}{|l|}{ EPA } \\
\hline $0.00-0.09 \mathrm{~g} / \mathrm{d}$ & 1 & & 1 & \\
\hline $0.09-0.14 \mathrm{~g} / \mathrm{d}$ & 0.86 & $0.69,1.06$ & 0.87 & $0.70,1.08$ \\
\hline $0.14-0.20 \mathrm{~g} / \mathrm{d}$ & 0.82 & $0.67,1.02$ & 0.86 & $0.69,1.08$ \\
\hline $0.20-0.28 \mathrm{~g} / \mathrm{d}$ & 0.81 & $0.66,1.01$ & 0.86 & $0.69,1.08$ \\
\hline$>0.28 \mathrm{~g} / \mathrm{d}$ & 0.81 & $0.66,1.01$ & 0.84 & $0.66,1.06$ \\
\hline \multicolumn{5}{|l|}{ DPA } \\
\hline $0.00-0.05 \mathrm{~g} / \mathrm{d}$ & 1 & & 1 & \\
\hline $0.05-0.07 \mathrm{~g} / \mathrm{d}$ & 0.95 & $0.77,1.18$ & 0.98 & $0.78,1.22$ \\
\hline $0.07-0.09 \mathrm{~g} / \mathrm{d}$ & 0.92 & $0.74,1 \cdot 13$ & 0.94 & $0.74,1.18$ \\
\hline $0.09-0.11 \mathrm{~g} / \mathrm{d}$ & 0.92 & $0.75,1.14$ & 0.90 & $0.71,1.15$ \\
\hline$>0.11 \mathrm{~g} / \mathrm{d}$ & 0.92 & $0.75,1.14$ & 0.89 & $0.68,1.16$ \\
\hline \multicolumn{5}{|l|}{ DHA } \\
\hline $0.00-0.23 \mathrm{~g} / \mathrm{d}$ & 1 & & 1 & \\
\hline $0.23-0.35 \mathrm{~g} / \mathrm{d}$ & 0.83 & $0.67,1.03$ & 0.84 & $0.68,1.04$ \\
\hline $0.35-0.48 \mathrm{~g} / \mathrm{d}$ & 0.81 & $0.66,1.00$ & 0.84 & $0.68,1.05$ \\
\hline $0.48-0.65 \mathrm{~g} / \mathrm{d}$ & 0.86 & $0.70,1.06$ & 0.88 & $0.70,1.11$ \\
\hline$>0.65 \mathrm{~g} / \mathrm{d}$ & 0.81 & $0.66,1.01$ & 0.81 & $0.63,1.03$ \\
\hline
\end{tabular}

among men. All data from the hospital discharge register were validated through review of every single medical record with reviewers blinded with regard to the $n$-3 PUFA intake among the patients. Finally, we had information on several potential confounders for which we adjusted in the statistical analyses.

The study also had limitations. We registered food intake 1 year before recruitment and it is possible that participants changed their dietary habits during the study period. We excluded all participants with ACS before the study period, but not participants with other CVD. Often, a change to a healthier diet is precipitated by symptoms, or the ascertainment, of a disease; for example, an individual who experiences angina pectoris may increase the intake of fish. If there is a beneficial effect of fish on development of ACS, such an effect would lead to an underestimation of an association in the present study. Stratification by the time from recruitment until onset of ACS showed a stronger negative association between dietary $n$-3 PUFA and ACS among men who experienced ACS more than 2 years after recruitment. This might indicate that some cases increased their intake of $n$-3 PUFA due to symptoms preceding diagnosis of ACS and thus weakened the negative associations between $n$-3 PUFA intake and ACS. The number of events in women was insufficient to confirm or reject an association between the intake of $n-3$ PUFA and ACS.

Although we adjusted for several potential confounders, residual confounding must be considered. Cundiff et al. reported that intake of $n-3$ PUFA was positively correlated to a nutrient intake profile with a lower CHD risk, when they examined lifestyle and dietary factors of 1441 diabetics $^{(34)}$. The authors hypothesised that the negative association between fish consumption and ACS, found in previous cohort studies, may have been due to confounding because these studies seldom have adjusted for dietary intake of other nutrients known to be risk factors of CHD. In the present study, however, adjustments for both dietary and non-dietary confounders did not substantially affect the estimates. Residual confounding thus seems to be an unlikely explanation for the findings in the present study.

We found different results for men and women. Only a few previous studies have examined the association between intake of marine n-3 PUFA and incidence of ACS among healthy women. In the Nurses' Health Study, including 1513 incident cases of CHD, a dose-dependent negative association between intake of long-chain $n$-3 PUFA and CHD was reported ${ }^{(20)}$. In both an Italian case-control study and a cohort study from Japan there was a negative association between intake of $n$-3 PUFA and $\mathrm{MI}^{(21,22)}$. In contrast, there was no effect on the risk of major coronary events of supplementation with $1800 \mathrm{mg}$ EPA daily among female participants in the Japan Eicosapentaenoic Acid Lipid Intervention Study ${ }^{(14)}$

In the present study, the age distribution was the same for both sexes, but the number of female cases was substantially lower than that of men, probably because women in general are older when they experience $\mathrm{ACS}^{(35,36)}$. Therefore, the

Table 4. Hazard ratios (HR) of acute coronary syndrome associated with intake of total marine $n$-3 PUFA, EPA, DHA and docosapentaenoic acid (DPA) among female participants in the Danish Diet, Cancer and Health cohort study*

(Hazard ratios and $95 \%$ confidence intervals)

\begin{tabular}{lllll}
\hline Quintile & HR & $95 \% \mathrm{Cl}$ & HR (adjusted) $\dagger$ & $95 \% \mathrm{Cl}$ \\
\hline$n$-3PUFA & & & & \\
$0.00-0.38 \mathrm{~g} / \mathrm{d}$ & 1 & & 1 & \\
$0.38-0.57 \mathrm{~g} / \mathrm{d}$ & 0.78 & $0.53,1.13$ & 0.85 & $0.57,1.26$ \\
$0.57-0.76 \mathrm{~g} / \mathrm{d}$ & 0.97 & $0.66,1.42$ & 1.09 & $0.73,1.63$ \\
$0.76-1.02 \mathrm{~g} / \mathrm{d}$ & 1.21 & $0.83,1.77$ & 1.31 & $0.86,1.98$ \\
$>1.03 \mathrm{~g} / \mathrm{d}$ & 0.94 & $0.65,1.38$ & 0.97 & $0.62,1.52$ \\
EPA & & & & \\
$0.00-0.08 \mathrm{~g} / \mathrm{d}$ & 1 & & 1 & \\
$0.08-0.13 \mathrm{~g} / \mathrm{d}$ & 0.88 & $0.60,1.28$ & 0.92 & $0.62,1.36$ \\
$0.13-0.19 \mathrm{~g} / \mathrm{d}$ & 1.00 & $0.68,1.46$ & 1.11 & $0.75,1.66$ \\
$0.19-0.24 \mathrm{~g} / \mathrm{d}$ & 1.44 & $0.99,2.11$ & 1.57 & $1.04,2.38$ \\
$>0.24 \mathrm{~g} / \mathrm{d}$ & 0.92 & $0.63,1.34$ & 0.93 & $0.60,1.42$ \\
DPA & & & & \\
$0.00-0.04 \mathrm{~g} / \mathrm{d}$ & 1 & & 1 & \\
$0.04-0.06 \mathrm{~g} / \mathrm{d}$ & 0.71 & $0.48,1.03$ & 0.73 & $0.49,1.10$ \\
$0.06-0.07 \mathrm{~g} / \mathrm{d}$ & 1.03 & $0.71,1.51$ & 1.12 & $0.74,1.71$ \\
$0.07-0.09 \mathrm{~g} / \mathrm{d}$ & 0.90 & $0.62,1.31$ & 0.93 & $0.60,1.45$ \\
$>0.09 \mathrm{~g} / \mathrm{d}$ & 0.98 & $0.67,1.44$ & 0.98 & $0.60,1.60$ \\
DHA & & & & \\
$0.00-0.20 \mathrm{~g} / \mathrm{d}$ & 1 & & 1 & \\
$0.20-0.32 \mathrm{~g} / \mathrm{d}$ & 0.77 & $0.53,1.13$ & 0.83 & $0.56,1.23$ \\
$0.32-0.43 \mathrm{~g} / \mathrm{d}$ & 0.97 & $0.66,1.42$ & 1.10 & $0.74,1.65$ \\
$0.43-0.59 \mathrm{~g} / \mathrm{d}$ & 1.00 & $0.68,1.46$ & 1.05 & $0.70,1.60$ \\
$>0.59 \mathrm{~g} / \mathrm{d}$ & 0.98 & $0.67,1.43$ & 1.00 & $0.64,1.57$ \\
\hline
\end{tabular}

${ }^{*}$ Based on Cox proportional hazard models. We used the lowest quintiles as reference.

† Adjusted for smoking, BMI, time of moderate to vigorous physical activity, history of diabetes mellitus, systolic blood pressure, total cholesterol, alcohol consumption, total intake of fruit, vegetables, saturated fat, monounsaturated fat and $n-6$ PUFA. Analyses were also adjusted for hormone replacement therapy. 
estimate of an association between dietary n-3 PUFA and ACS among women is statistically uncertain which may, at least in part, explain the different results. Finally, previous studies have reported sex differences in presentation of symptoms, results from diagnostic tests, effect of treatment, complication of ACS, presentation of risk factors, and different impact from known risk factors for $\mathrm{ACS}^{(35,37-39)}$.

The associations between EPA, DHA and DPA per se and ACS were approximately the same as for total $n$-3 PUFA. EPA, DHA and DPA are differently distributed into various tissues and are only converted to each other to a limited degree $^{(40,41)}$. It is therefore possible that each fatty acid has individual effects on the risk of CHD, but the difference in effects of EPA and DHA has been examined in very few studies $^{(42,43)}$. The biological effects of DPA, apart from being a possible intermediate between EPA and DHA, are almost unknown ${ }^{(44-46)}$.

We found no dose-response relationship between consumption of marine $n-3$ PUFA and ACS. For men we found a threshold effect where men with an intake of more than $0.4 \mathrm{~g} n$-3 PUFA per d had an approximately $15 \%$ lower risk of ACS compared with those with a lower intake of $n-3$ PUFA. These results are in line with the results from a meta-analysis by König et al. ${ }^{(47)}$ who found that an intake of $100 \mathrm{~g}$ fish per week was associated with a $25 \%$ lower risk of non-fatal MI compared with a lower fish intake and that a higher fish intake was not associated with further risk reduction. A threshold effect may help explain why some previous cohort studies with a lower average intake than $0.4 \mathrm{~g} n-3$ PUFA per $\mathrm{d}$ did not find a negative association between intake of marine $n-3$ PUFA and $\mathrm{CHD}^{(2,18)}$. Arterburn et al. ${ }^{(40)}$ previously reported that dietary intake of DHA increased the concentration of DHA in plasma up to a threshold of $2 \mathrm{~g} / \mathrm{d}$ (ten-fold higher than in the present study), but an intake above this amount only increased the plasma concentration of DHA marginally. These findings were, however, not supported by a clinical trial by Christensen et al. who found a dose-dependent association between intake of marine $n-3$ PUFA and tissue content of EPA and $\mathrm{DHA}^{(48)}$. Moreover, the threshold found in the present study ( $0.4 \mathrm{~g} \mathrm{n}$-3 PUFA per d) is substantially lower than the level where studies have documented an effect of $n$-3 PUFA on risk factors for ACS, including lowering of plasma TAG, blood pressure, platelet aggregation, inflammatory markers, and improved vascular reactivity ${ }^{(49)}$.

In contrast to our findings, both a Japanese cohort study, where the participants had a high $n-3$ PUFA intake ${ }^{(21)}$, and an American cohort study among women with a low intake of $n-3$ PUFA $^{(20)}$ found a dose-response relationship between $n$-3 PUFA and MI. Studies on CHD mortality also have shown dose-dependent preventive effects of dietary intake of fish and $n-3$ PUFA $^{(50)}$. Among the studies of $n-3$ PUFA there are considerable differences in the methods of assessing the $n-3$ PUFA content of the food and this may partly explain the different conclusions.

In conclusion, we found a borderline significant negative association between intake of total and specific $n$-3 PUFA and ACS among healthy men. Among females we found no association, but the number of events was insufficient to confirm or reject an association between the intake of $n$-3 PUFA and ACS.

\section{Acknowledgements}

The authors' responsibilities were as follows: A. M. J. was involved in the analytic strategy, analysed the data, validated the outcome data, conducted the interpretation of data and wrote the first draft of the manuscript; E. B. S. was involved in the design of the study; C. D. was involved in the design of the analytic strategy; K. O. and A. T. established the original study cohort; K. O. was involved in the design of the study and analytic strategy. All authors contributed to the interpretation of data and critical revision of the manuscript.

None of the authors had a financial or personal conflict of interest.

\section{References}

1. Beaglehole R (1999) International trends in coronary heart disease mortality and incidence rates. J Cardiovasc Risk 6, 63-68.

2. Albert CM, Hennekens CH, O'Donnell CJ, et al. (1998) Fish consumption and risk of sudden cardiac death. JAMA 279, $23-28$.

3. Marchioli R, Barzi F, Bomba E, et al. (2002) Early protection against sudden death by $n-3$ polyunsaturated fatty acids after myocardial infarction: time-course analysis of the results of the Gruppo Italiano per lo Studio della Sopravvivenza nell'Infarto Miocardico (GISSI)-Prevenzione. Circulation 105, 1897-1903.

4. Siscovick DS, Raghunathan TE, King I, et al. (1995) Dietary intake and cell membrane levels of long-chain $n$-3 polyunsaturated fatty acids and the risk of primary cardiac arrest. JAMA 274, 1363-1367.

5. Christensen JH \& Schmidt EB (2001) n-3 Fatty acids and the risk of sudden cardiac death. Lipids 36, Suppl., S115-S118.

6. Daviglus ML, Stamler J, Orencia AJ, et al. (1997) Fish consumption and the 30-year risk of fatal myocardial infarction. $N$ Engl J Med 336, 1046-1053.

7. Yuan JM, Ross RK, Gao YT, et al. (2001) Fish and shellfish consumption in relation to death from myocardial infarction among men in Shanghai, China. Am J Epidemiol 154, 809-816.

8. Kromhout D, Bosschieter EB \& de Lezenne CC (1985) The inverse relation between fish consumption and 20-year mortality from coronary heart disease. N Engl J Med 312, 1205-1209.

9. Bucher HC, Hengstler P, Schindler C, et al. (2002) n-3 Polyunsaturated fatty acids in coronary heart disease: a meta-analysis of randomized controlled trials. Am J Med 112, 298-304.

10. Hooper L, Thompson RL, Harrison RA, et al. (2006) Risks and benefits of omega 3 fats for mortality, cardiovascular disease, and cancer: systematic review. BMJ 332, 752-760.

11. Wang C, Harris WS, Chung M, et al. (2006) n-3 Fatty acids from fish or fish-oil supplements, but not $\alpha$-linolenic acid, benefit cardiovascular disease outcomes in primary- and secondaryprevention studies: a systematic review. Am J Clin Nutr 84, $5-17$.

12. Burr ML, Fehily AM, Gilbert JF, et al. (1989) Effects of changes in fat, fish, and fibre intakes on death and myocardial reinfarction: diet and reinfarction trial (DART). Lancet ii, 757-761.

13. Burr ML, Ashfield-Watt PA, Dunstan FD, et al. (2003) Lack of benefit of dietary advice to men with angina: results of a controlled trial. Eur J Clin Nutr 57, 193-200.

14. Yokoyama M, Origasa H, Matsuzaki M, et al. (2007) Effects of eicosapentaenoic acid on major coronary events in hypercholesterolaemic patients (JELIS): a randomised open-label, blinded endpoint analysis. Lancet 369, 1090-1098.

15. Svensson M, Schmidt EB, Jorgensen KA, et al. (2006) n-3 Fatty acids as secondary prevention against cardiovascular events in 
patients who undergo chronic hemodialysis: a randomized, placebo-controlled intervention trial. Clin J Am Soc Nephrol 1, $780-786$.

16. Schmidt EB, Arnesen H, de Caterina R, et al. (2005) Marine $n-3$ polyunsaturated fatty acids and coronary heart disease. Part I. Background, epidemiology, animal data, effects on risk factors and safety. Thromb Res 115, 163-170.

17. Robinson JG \& Stone NJ (2006) Antiatherosclerotic and antithrombotic effects of omega-3 fatty acids. Am J Cardiol 98, $39 \mathrm{i}-49 \mathrm{i}$.

18. Ascherio A, Rimm EB, Stampfer MJ, et al. (1995) Dietary intake of marine $n-3$ fatty acids, fish intake, and the risk of coronary disease among men. $N$ Engl J Med 332, 977-982.

19. Pietinen P, Ascherio A, Korhonen P, et al. (1997) Intake of fatty acids and risk of coronary heart disease in a cohort of Finnish men. The Alpha-Tocopherol, Beta-Carotene Cancer Prevention Study. Am J Epidemiol 145, 876-887.

20. Hu FB, Bronner L, Willett WC, et al. (2002) Fish and omega-3 fatty acid intake and risk of coronary heart disease in women. JAMA 287, 1815-1821.

21. Iso H, Kobayashi M, Ishihara J, et al. (2006) Intake of fish and $\mathrm{n} 3$ fatty acids and risk of coronary heart disease among Japanese: the Japan Public Health Center-Based (JPHC) Study Cohort I. Circulation 113, 195-202.

22. Tavani A, Pelucchi C, Negri E, et al. (2001) n-3 Polyunsaturated fatty acids, fish, and nonfatal acute myocardial infarction. Circulation 104, 2269-2272.

23. Harris WS, Poston WC \& Haddock CK (2007) Tissue $n-3$ and $n-6$ fatty acids and risk for coronary heart disease events. Atherosclerosis 193, 1-10.

24. Block RC, Harris WS, Reid KJ, et al. (2008) EPA and DHA in blood cell membranes from acute coronary syndrome patients and controls. Atherosclerosis 197, 821-828.

25. Harris WS, Reid KJ, Sands SA, et al. (2007) Blood omega-3 and trans fatty acids in middle-aged acute coronary syndrome patients. Am J Cardiol 99, 154-158.

26. Sun Q, Ma J, Campos H, et al. (2008) Blood concentrations of individual long-chain $n-3$ fatty acids and risk of nonfatal myocardial infarction. Am J Clin Nutr 88, 216-223.

27. Aarsetoey H, Ponitz V, Grundt H, et al. (2009) (n-3) Fatty acid content of red blood cells does not predict risk of future cardiovascular events following an acute coronary syndrome. $J$ Nutr 139, 507-513.

28. Tjonneland A, Olsen A, Boll K, et al. (2007) Study design, exposure variables, and socioeconomic determinants of participation in Diet, Cancer and Health: a population-based prospective cohort study of 57053 men and women in Denmark. Scand J Public Health 35, 432-441.

29. Tjonneland A, Overvad K, Haraldsdottir J, et al. (1991) Validation of a semiquantitative food frequency questionnaire developed in Denmark. Int J Epidemiol 20, 906-912.

30. Overvad K, Tjonneland A, Haraldsdottir J, et al. (1991) Development of a semiquantitative food frequency questionnaire to assess food, energy and nutrient intake in Denmark. Int J Epidemiol 20, 900-905.

31. Joensen AM, Jensen MK, Overvad K, et al. (2009) Predictive values of acute coronary syndrome discharge diagnoses differed in the Danish National Patient Registry. J Clin Epidemiol 62, 188-194.

32. Luepker RV, Apple FS, Christenson RH, et al. (2003) Case definitions for acute coronary heart disease in epidemiology and clinical research studies: a statement from the AHA Council on Epidemiology and Prevention; AHA Statistics Committee; World Heart Federation Council on Epidemiology and
Prevention; the European Society of Cardiology Working Group on Epidemiology and Prevention; Centers for Disease Control and Prevention; and the National Heart, Lung, and Blood Institute. Circulation 108, 2543-2549.

33. Tjonneland A, Overvad K, Thorling E, et al. (1993) Adipose tissue fatty acids as biomarkers of dietary exposure in Danish men and women. Am J Clin Nutr 57, 629-633.

34. Cundiff DK, Lanou AJ \& Nigg CR (2007) Relation of omega-3 fatty acid intake to other dietary factors known to reduce coronary heart disease risk. Am J Cardiol 99, 1230-1233.

35. Anand SS, Islam S, Rosengren A, et al. (2008) Risk factors for myocardial infarction in women and men: insights from the INTERHEART study. Eur Heart J 29, 932-940.

36. Shaw LJ, Bairey Merz CN, Pepine CJ, et al. (2006) Insights from the NHLBI-sponsored Women's Ischemia Syndrome Evaluation (WISE) Study: part I: gender differences in traditional and novel risk factors, symptom evaluation, and gender-optimized diagnostic strategies. J Am Coll Cardiol 47, Suppl. 3, S4-S20.

37. Lovlien M, Schei B \& Hole T (2006) Women with myocardial infarction are less likely than men to experience chest symptoms. Scand Cardiovasc J 40, 342-347.

38. Elsaesser A \& Hamm CW (2004) Acute coronary syndrome: the risk of being female. Circulation 109, 565-567.

39. Quyyumi AA (2006) Women and ischemic heart disease: pathophysiologic implications from the Women's Ischemia Syndrome Evaluation (WISE) Study and future research steps. J Am Coll Cardiol 47, Suppl. 3, S66-S71.

40. Arterburn LM, Hall EB \& Oken H (2006) Distribution, interconversion, and dose response of $n-3$ fatty acids in humans. Am J Clin Nutr 83, Suppl. 6, 1467S-1476S.

41. Gerster H (1998) Can adults adequately convert $\alpha$-linolenic acid $(18: 3 n-3)$ to eicosapentaenoic acid (20:5n-3) and docosahexaenoic acid (22:6n-3)? Int J Vitam Nutr Res 68, 159-173.

42. Grimsgaard S, Bonaa KH, Hansen JB, et al. (1997) Highly purified eicosapentaenoic acid and docosahexaenoic acid in humans have similar triacylglycerol-lowering effects but divergent effects on serum fatty acids. Am J Clin Nutr 66, 649-659.

43. Grimsgaard S, Bonaa KH, Hansen JB, et al. (1998) Effects of highly purified eicosapentaenoic acid and docosahexaenoic acid on hemodynamics in humans. Am J Clin Nutr 68, 52-59.

44. Simon JA, Hodgkins ML, Browner WS, et al. (1995) Serum fatty acids and the risk of coronary heart disease. Am J Epidemiol 142, 469-476.

45. Pedersen JI, Ringstad J, Almendingen K, et al. (2000) Adipose tissue fatty acids and risk of myocardial infarction a case-control study. Eur J Clin Nutr 54, 618-625.

46. Virtanen JK, Voutilainen S, Rissanen TH, et al. (2005) Mercury, fish oils, and risk of acute coronary events and cardiovascular disease, coronary heart disease, and all-cause mortality in men in eastern Finland. Arterioscler Thromb Vasc Biol 25, 228-233.

47. König A, Bouzan C, Cohen JT, et al. (2005) A quantitative analysis of fish consumption and coronary heart disease mortality. Am J Prev Med 29, 335-346.

48. Christensen JH, Christensen MS, Dyerberg J, et al. (1999) Heart rate variability and fatty acid content of blood cell membranes: a dose-response study with $n-3$ fatty acids. Am J Clin Nutr 70, 331-337.

49. Breslow JL (2006) n-3 Fatty acids and cardiovascular disease. Am J Clin Nutr 83, Suppl. 6, 1477S-1482S.

50. He K, Song Y, Daviglus ML, et al. (2004) Accumulated evidence on fish consumption and coronary heart disease mortality: a meta-analysis of cohort studies. Circulation 109, 2705-2711. 